\title{
A Importância da Gestão Estratégica de Pessoas no Âmbito Organizacional
}

\section{The Importance of Strategic People Management in the Organizational Scope}

\author{
Bruno Gomes de Sousa*a; Marcos Aurélio Cavalcante Ayres ${ }^{\mathrm{a}}$; Maycon da Cruz Marinho ${ }^{\mathrm{b}}$; Rogério Sales Silvac; \\ Thiago Sousa ${ }^{a}$
}

\author{
${ }^{a}$ Universidade Estadual da Região Tocantina do Maranhão, Curso de Administração. MA, Brasil. \\ bUnidade de Ensino Superior do Sul do Maranhão. MA, Brasil. \\ 'UNISULMA, Curso de Administração. MA, Brasil. \\ *E-mail: bruno.mrbr@outlook.com
}

\begin{abstract}
Resumo
O advento da globalização, especificamente, no que se refere à esfera empresarial permitiu a adoção de importantes mudanças em se tratando da gestão administrativa das empresas. Tais mudanças se referem, principalmente, à forma como se encaram as pessoas que compõem as empresas. Acredita-se que sejam as pessoas a parte essencial de todas as empresas. Este artigo pretendeu discutir sobre a importância das pessoas, bem como de saber qual a forma de lidar com elas e como isto pode influenciar, positiva ou negativamente, nos resultados das empresas. Assim, observa-se que para gerir as pessoas não se deve ter apenas visão mecanicista ou mesmo metódica, é necessário que se discuta e compreendam as diferenças existentes entre técnicas obsoletas antigas e as modernas, que atuam conjuntamente com uma gestão eficaz. Precisa ser resgatado o papel que o ser humano representa dentro das organizações quanto a sua atuação nas atividades que executa como colaboradores dentro das empresas. Tal atitude, por parte das organizações, lhes permitirá ver que o capital humano poderá ser o seu grande diferencial em se tratando de competitividade. Diante do exposto, o artigo foi desenvolvido baseado em diversas literaturas bibliográficas, apresentando uma análise da importância da gestão de pessoas para as organizações, bem como demonstrar o quanto elas possuem um reflexo positivo nos resultados finais das empresas. Afinal, quando uma gestão de pessoas é eficaz, aliada ao processo de gestão da inovação e conhecimento terá condição de garantir muitas vantagens competitivas, que podem ser difíceis ou mesmo impossíveis de serem copiadas pelas empresas concorrentes.
\end{abstract}

Palavras-chave: Empresa. Gestão de Pessoas. Globalização. Resultado.

\begin{abstract}
The advent of globalization, specifically regarding the business sphere, has allowed the adoption of important changes in the companies administrative management. These changes are mainly related to the way the people who make up the companies are viewed. It is believed that people are the essential part of all businesses. This article aimed to discuss the people's importance as well as to know how to deal with them and how this can influence positively or negatively in the companies' results. Thus, it should be noted that in order to manage people one should not only have a mechanistic or even methodical view, it is necessary to discuss and understand the differences between old and modern obsolete techniques that work together with effective management. The role needs to be rescued that the human being represents within the organizations as to their performance in the activities that perform as collaborators within the companies. Such an attitude on the part of the organizations will allow them to see that human capital can be their great differential when it comes to competitiveness. Considering the above, the article sought based on several bibliographical literatures, present an analysis of the importance of people management for organizations, as well as demonstrate how they have a positive reflection on the companies'final results. After all, when people management is effective, allied to the process of managing innovation and knowledge will be able to guarantee many competitive advantages that may be difficult or even impossible to be copied by the competing companies.
\end{abstract}

Keywords: Company. People Management. Globalization. Result.

\section{Introdução}

Nos dias atuais se observa que Mundo tem passado pelo processo de modernização provocado pela globalização, isto é fato, especificamente, nos planos tecnológico, das comunicações e econômico, e por esta razão se têm provocado inúmeras mudanças na gestão administrativa das organizações.

É oportuno afirmar que a chave do sucesso ou insucesso para as estratégias de qualquer empresa são os seres humanos, pois são eles que dão vida aos inúmeros processos das organizações. Por motivos assim, é que na maioria das empresas de sucesso, o ser humano é considerado como a única e grande vantagem competitiva eminentemente sustentável.

Dessa forma, para o ser humano se tornar de fato a peça central e principal de uma gestão empresarial, é preciso que o foco esteja nas relações humanas e no ambiente de trabalho. A gestão de pessoas defende que por intermédio de tais comandos é possível compreender a natureza real das empresas, bem como as suas possibilidades reais de melhoria, tendo como base um planejamento adequado, incluindo neste as pessoas como bens maiores.

A Administração de Recursos Humanos é algo ainda bem recente, uma vez que iniciou em meados do século XX, mais especificamente, após o advento da Revolução Industrial, porém dessa época para cá veio sofrendo importantes modificações e sendo aperfeiçoada. No entanto, é importante lembrar que o processo de gestão de pessoas visa com essa 
ferramenta atingir a valorização dos profissionais, e porque não dizer dos seres humanos, diferentemente do setor de Recursos Humanos, o qual visava apenas a técnica e o mecanicismo destes profissionais.

Quando se fala em administrar pessoas, Kotter (2009) se reporta a convivência dos seres humanos, que compõem uma empresa, uma vez que é nessas em que passam a maior parte das suas vidas, prestando a estes seus preciosos serviços. A partir desta ótica, é possível afirmar que a produção de bens e serviços de uma organização não poderia ser jamais executado por pessoas, que trabalham individualmente.

As empresas são formadas por equipes ou grupos de pessoas das quais dependem para atingir suas metas. Já com relação às pessoas, a empresa é vista como o caminho para conquistarem muitos objetivos de realização pessoal. De fato, são as pessoas a essência das empresas.

A presente pesquisa bibliográfica tem por objetivo discutir sobre a importância que as pessoas têm para as empresas, bem como destacar sobre saber lidar com elas e que poderá influenciar nos resultados obtidos pelas organizações. Pretendeu-se, ainda, com a pesquisa, abrir caminhos para outras pesquisas interligadas a este tema, e/ou suas peculiaridades.

\section{Desenvolvimento}

\subsection{Metodologia}

A metodologia adotada consistiu na revisão de literatura para conceituar e definir gestão de pessoas. "A citação das principais conclusões a que outros autores chegaram permite salientar a contribuição da pesquisa realizada e demonstrar contradições ou reafirmar comportamentos e atitudes" (LAKATOS; MARCONI, 2010, p.208).

No que tange às fontes foram buscados livros e artigos por apresentarem embasamento técnico e científico. Para esta pesquisa, especificamente, será utilizada uma metodologia de cunho qualitativo, baseado em um aporte bibliográfico como bem cita Gil (2010, p.50). A pesquisa bibliográfica se desenvolve a partir de análise de material anteriormente elaborado e constituído, principalmente, por meio de livros, de revistas, de artigos científicos, entre outros.

De acordo com Gil (2010, p.51): “A principal vantagem da pesquisa bibliográfica reside no fato de permitir ao investigador a cobertura de uma gama de fenômenos muito mais ampla do que aquela que poderia pesquisa diretamente". Essa cobertura, por sua vez, contribuiu com a diversidade de autorias e referências acerca do tema em questão.

\subsection{Gestão de pessoas}

Até bem pouco tempo, a área de recursos humanos atuava muito mecanicamente, em que as empresas esperavam dos seus empregados, obediência e que estes executassem tarefas e que os chefes possuíssem poder centralizado. Nos dias atuais se tem um panorama bem diferente, pois em lugar de funcionários e dos chefes se encontram colaboradores e gestores.

Para gerir pessoas não se pode jamais usar visão metódica ou mecanicista, é necessário que se discuta e compreenda as diferenças existentes entre técnicas modernas e a gestão da inovação e do conhecimento (MARRAS, 2000).

Segundo enfoca Neto et al (2005), no passado, época em que as mudanças ocorriam paulatinamente, quase ninguém questionava a legitimidade e nem as formas como ocorria a gestão das empresas. Contudo, os tempos mudaram e, atualmente, na velocidade em que ocorrem as transformações é muito constante. Desse modo, tem-se a importância de haver flexibilidade para que sejam modificados os conceitos, as referências e os modelos de gestão para não comprometer o sucesso nas ações empresariais.

[...] a função de recursos humanos como parceira estratégica da organização inclui a participação desta área na formulação das estratégias da empresa, assim como na implementação dessa estratégia por meio da aplicação consistente dos instrumentos de Gestão de Pessoas (DESSLER, 2004, p. 89).

Em decorrência do avanço da tecnologia que aconteceu ao final do século XX e início deste século, período em que a produção de bens e serviços oferecidos aos clientes passa a ter maior exigência de conhecimentos, bem como de recursos tecnológicos. O trabalhador antes da Era Industrial era considerado como fator de produção, passou então a partir daí a ser entendido, finalmente, como Trabalhador do Conhecimento (DRUCKER, 2002).

Segundo entende Fischer (2002, p. 125), o modelo de gestão de pessoas começou a se transformar nas organizações, adquirindo nova importância. Resumindo, o autor afirma que “[...] os novos modelos originaram-se com uma administração burocrática e controladora, realizada pelos Departamentos de Pessoal".

O planejamento da alocação de pessoas, o treinamento, os processos de recrutamento e seleção, metodologias de avaliação dos empregados e políticas de remuneração e benefícios passaram a ser as principais funções dos Departamentos de Recursos Humanos.

\subsection{A gestão estratégica de pessoas}

A gestão estratégica pressupõe a importância e necessidade de um processo decisório, a partir de estudos e análises dos ambientes: interno e externo das empresas, os quais proporcionarão a tomada de decisões capazes de melhorar o futuro das empresas. É possível serem observados três níveis hierárquicos de grande importância quando se trata de gestão ou planejamento estratégico, como destaca o autor, a saber: gestão estratégica de unidades de negócio; gestão estratégica corporativa e a gestão estratégica de áreas ou processos funcionais (MAXIMIANO, 2014).

Segundo Maximiano (2014), o gestor gerenciará pessoas nas empresas o tempo todo, mesmo sendo estas uma equipe de uma pequena empresa ou até uma multinacional. O grande 
desafio das empresas, nos dias de hoje, é conseguir incentivar, motivar seus funcionários, fazendo com que seus objetivos sejam também os da organização e que o trabalho, além de sustento, também seja muito prazeroso.

[...] um gerenciamento de pessoas é eficaz quando este funciona como sustentáculo para as organizações prestar serviços com qualidade, sendo também capaz de promover a ciência e os valores humanos, em busca de uma sociedade mais justa, visando ao desenvolvimento sustentável de nosso país (LACOMBE, 2005, p. 50).

Nos dias atuais se percebe uma sociedade baseada no conhecimento, na qual os talentos e capacidades humanas passam a serem vistas como quesitos de competitividade no mercado de trabalho. Entretanto, diferentemente do que têm acontecido, esses quesitos deverão ser vistos e analisados pelos olhares dos colaboradores e não pelos dos concorrentes. É necessário que seja resgatado o papel do ser humano dentro das organizações, objetivando com isso torná-los cada vez mais competentes diante da execução das suas atividades como colaboradores. Agindo assim, a organização perceberá que o capital humano poderá ser seu grande diferencial em se tratando de competitividade (GILSON, 2011).

Quando realizada corretamente, a gestão de pessoas se tornará em uma excelente vantagem competitiva, uma vez que a empresa que possui funcionários satisfeitos funciona indiscutivelmente melhor.

O ponto de partida é a formação de uma equipe competente: a qualidade do pessoal admitido é crítica. É preciso que não seja fácil para os competidores conseguir uma equipe com a mesma qualidade; a seguir, a condução dessa equipe para motivá-la e obter a lealdade e o comprometimento com a empresa e, finalmente seu desenvolvimento para aprimorar sua competência e conhecimento, por meio de programas de treinamento formais e informais (LACOMBE, 2005, p. 362).

Segundo Demo (2015), o treinamento é considerado como o mais importante fator crítico de sucesso de uma empresa que vive na era do conhecimento. Entretanto, é necessário que as organizações formulem e coordenem um plano de capacitação anual destinado ao desenvolvimento dos colaboradores. É preciso também desenvolver ações voltadas para formar gerentes com postura participativa, dotados de capacidade de orientar e estimular o desempenho dos seus colaboradores, por meio de mecanismos que avaliem o nível de satisfação dos funcionários, bem como os indicadores organizacionais, além de ainda possuir ações que identifiquem, analisem e/ou solucionem possíveis problemas.

Percebe-se que entre os muitos avanços, que ocorreram nos últimos anos, e que têm levado as empresas a irem à busca de novas maneiras de gestão na tentativa de aprimorar seus desempenhos, alcançando com isso melhores resultados para atingir sua missão, enquanto instituição. Somando a tais fatores se observa o pleno atendimento das inúmeras necessidades dos seus clientes. Dessa forma, é possível afirmar que o sucesso das empresas dependerá dos investimentos destas nas pessoas que a compõem, aproveitando seus potenciais, identificando suas qualidades e desenvolvendo nestas, seu capital intelectual (CHIAVENATO, 2007).

A vantagem competitiva real no mercado, segundo destaca o autor, não está representada tão somente no setor financeiro, nem menos nos altos investimentos em tecnologias e/ou maquinário, mas sim nas pessoas que fazem parte das organizações e que as movimentam no dia a dia.

É importante que o gestor de pessoas tenha em mente uma perspectiva do que ele quer, ele precisa também pensar sobre o futuro, daí a necessidade de ocorrer um planejamento estratégico adequado que deixe metas e objetivos bem claros. No entanto, para que isso aconteça, é importante haver a participação de todo pessoal que faz parte da empresa o que torna o espírito de equipe essencial para a sobrevivência da empresa (SOVIESNKI; STIGAR, 2008).

Cabe ao gestor funcionar também como facilitador, pois, dessa forma, as relações ocorrerão dentro dos princípios e conforme a missão da instituição. Este diferencial irá, certamente, provocar uma motivação nas pessoas, tornandoas mais parceiras e não somente meros funcionários da organização, pois são seres humanos capacitados, dotados de inteligência e sentimentos, como: razão e emoção que precisam ser valorizados em todo contexto global, à medida em que forem vistos como colaboradores, as organizações terão uma produtividade maior, pois estarão envolvidos com resultados e metas das empresas.

Para que haja sucesso na empresa, é preciso que os objetivos da gestão estratégica de pessoas estejam claros e definidos. O que vai garantir a qualidade nas ações desenvolvidas é a motivação dos colaboradores. Desenvolver e estimular a qualidade de vida vem sendo um dos grandes desafios da atualidade em várias instituições e também nas próprias pessoas, visando além da produtividade e, o bem-estar social que a pessoa merece (SOVIENSKI; STIGAR, 2008, p.58).

Para garantir suas vantagens, de forma competitiva, através das pessoas, as empresas precisam investir em seus colaboradores, levando em conta o fato de que tudo que for feito com relação às estratégias mercadológicas poderá também ser copiado pelos seus concorrentes, exceto quando se tratar da capacidade de execução de seu pessoal, a fim de implementar suas ações estratégicas.

Proporcionar segurança ao pessoal no emprego; Alta seletividade na admissão; Remuneração elevada; Incentivos financeiros e não financeiros; Participação acionária ou nos lucros; Partilhar informações; Descentralização das decisões; Formulação de equipes e reformulação dos processos; Treinamento e desenvolvimento de habilidades; Rotação de função e ampliação do trabalho; Igualdade simbólica; Diminuição da importância da remuneração; Prioridade para promoções internas (LACOMBE, 2005, p. 220).

Todas as estratégias utilizadas pelas empresas são válidas para prover vantagem competitiva para as empresas por algum tempo, porém para ampliar o tempo dessas vantagens é necessária uma atenção especial à maneira de se administrar as pessoas.

Entretanto, não se deve ver os funcionários como meros 
técnicos ou recursos, como bem destaca, pois elas são seres humanos dotados de uma infinidade de fatores, tais como: emoção, inteligência, sentimentos, razão, etc., fatores estes que necessitam ser bem mais valorizados de forma integral, pois somente assim sendo considerados como parceiros ou corresponsáveis pela empresa, essa obterá maior produtividade e desenvolvimento (SOARES, 2010).

É possível perceber que as pessoas sentem prazer em seus trabalhos, entregando cada uma o melhor de si, desenvolvendo com isso suas habilidades mentais, suas criatividades, inteligências, proporcionando com isso autonomia, incentivando cada profissional a ir em busca do seu próprio crescimento. Reconhece-se que é possível manter as pessoas, que buscam o sucesso pessoal e o organizacional dentro das empresas.

\section{Conclusão}

Sabe-se que o ser humano vive em constante e contínuo processo de desenvolvimento, tanto em âmbito, histórico, cultural quanto social, sendo o que se espera dos seres dotados de inteligência. Entretanto, tal desenvolvimento necessita, primeiramente, entender o que de fato significa o que está ao redor da empresa, que são as pessoas. É importante lembrar que há fatores que implicam no desenvolvimento das empresas, tais como: costumes, hábitos, valores, linguagem e cultura, ou seja, observa-se que as pessoas acabam se desenvolvendo em ritmos e formas variadas e mais aceleradas.

Existe, portanto, uma grande diferença no âmbito empresarial nos dias de hoje, em que as empresas, independentemente dos seus vários setores ou serviços oferecidos, se compõem por grupos de pessoas com muitas diferenças, sejam culturais ou mesmo comportamentais. Entretanto, cabe destacar, segundo alguns autores, citados ao longo deste artigo, que: as pessoas de maneira geral, que compõem as empresas, devem estar lá com os objetivos comuns, daí a necessidade de serem estimuladas a manter um relacionamento bom com toda equipe, uma vez que tal atitude poderá resultar em lucratividade e perpetuação do capital das empresas.

Neste artigo se procurou fazer uma análise reflexiva sobre a importância da gestão estratégica de pessoas por ser esta uma ferramenta poderosa para as empresas e visto que elas refletem, positivamente, nos resultados das empresas. Reconhece-se que quando uma gestão de pessoas acontece, de forma eficaz, quando esta se alia à gestão da inovação e do conhecimento poderá garantir muitas vantagens competitivas para as empresas. Essas são estratégias quase impossíveis de serem copiadas pelas concorrências.

Percebeu-se com a pesquisa que são as pessoas a base de qualquer organização, assim se reconhece que elas de fato são o sustentáculo das organizações, prestando ali serviços de qualidade bem elevada, por isso que as pessoas merecem atenção das empresas, pois oferece, no ambiente de trabalho, qualidade nos serviços, levando com isso as empresas a caminharem rumo ao alcance dos seus objetivos. Cabe destacar que a presente pesquisa é apenas de cunho bibliográfico, a qual faz uma introdução breve a respeito do tema, que poderá servir como fonte de consulta para outros trabalhos.

Observa-se que os ambientes das organizações são cada vez mais dinâmicos e, por isso, requerem profissionais competentes, que sejam capazes de impulsionar tanto as pessoas quanto as próprias organizações rumo aos caminhos da produtividade, da lucratividade e dos bons resultados. Requer ainda que haja plena satisfação das necessidades humanas, qualidade de vida e responsabilidade socioambiental e institucional, isso com relação à empresa.

Certamente, o tema abordado é um grande e ousado desafio que precisa de muita atenção de todos e de cada um dos que compõem a empresa, a qual requer que os processos éticos e emancipatórios da instituição façam parte da construção de uma sociedade mais justa e humana, na qual o emprego e o trabalho possam se sobressair como fatores de construção e ampliação das possibilidades de uma vida mais digna.

Conclui-se que a estrutura e a cultura de uma organização sejam fatores importantes no processo de gestão de pessoas, uma vez que são dessas que resultam maior abertura para se implantarem estratégias novas e/ou mesmo engessar os velhos paradigmas. Por fim, observa-se que há grande necessidade de que o gestor estratégico de pessoas possa elaborar e reavaliar, constantemente, os modelos a se implantar nas organizações, pois a mudança é uma constante para a vida de todas as empresas, uma vez que promove transição e adaptação e que estas sejam características intrínsecas a todo e qualquer modelo de gestão em uma organização.

\section{Referências}

CHIAVENATO, I. Recursos humanos. São Paulo: Atlas, 2007.

DEMO, P. Pesquisa e construção de conhecimento. Rio de Janeiro: Tempo Brasileiro, 2015.

DESSLER, G. Administração de Recursos Humanos. São Paulo: Pearson, 2004.

DRUCKER, P. Administrando em tempos de mudanças. São Paulo: Pioneira Thomson Learning, 2002.

FISCHER. A.L. Um resgate conceitual e histórico dos modelos de gestão de pessoas. As Pessoas na organização. São Paulo: Gente, 2002.

GIL, A.C. Como elaborar projetos de pesquisa. São Paulo: Atlas, 2010.

GILSON, A importância das pessoas para as empresas. São Paulo: Atlas, 2011.

KOTTER, J.P. O que os gerentes gerais eficazes realmente fazem. Afinal, o que fazem os líderes: a nova face do poder e da estratégia. Rio de Janeiro: Campus, 2009.

LAKATOS, E.M..; MARCONI, M.A. Fundamentos de metodologia científica. São Paulo: Atlas, 2010.

LACOMBE, F.J.M. Recursos humanos: princípios e tendências. São Paulo: Saraiva, 2005.

MARRAS, J.P. Administração de recursos humanos: do 
operacional ao estratégico. São Paulo: Futura, 2000.

MAXIMIANO, A.C.A. Introdução à administração. São Paulo, Atlas, 2014.

NETO, C.P.S.B. et al. Gestão estratégica de pessoas. Rio de Janeiro: FGV. 2005.
SOARES, A.B.B. et al. Novas tecnologias aplicadas à gestão do conhecimento. Rio de Janeiro, 2010.

SOVIENSKI, F.; STIGAR, R. Recursos humanos x gestão de pessoas. Gestão, p. 58, 2008. 